\title{
Update Breast Cancer 2019 Part 2 - Implementation of Novel Diagnostics and Therapeutics in Advanced Breast Cancer Patients in Clinical Practice
}

\author{
Update Mammakarzinom 2019 Teil 2 - Implementierung \\ neuer Diagnostika und Therapien bei Patientinnen \\ mit fortgeschrittenem Brustkrebs in der klinischen Praxis
}

\section{(ㅇ)(1) (요 $\Theta$}

Authors

Wolfgang Janni ${ }^{1}$, Andreas Schneeweiss ${ }^{2}$, Volkmar Müller ${ }^{3}$, Achim Wöckel ${ }^{4}$, Michael P. Lux ${ }^{5}$, Andreas D. Hartkopf ${ }^{6}$, Naiba Nabieva ${ }^{5}$, Florin-Andrei Taran ${ }^{6}$, Hans Tesch ${ }^{7}$, Friedrich Overkamp ${ }^{8}$, Diana Lüftner ${ }^{9}$, Erik Belleville ${ }^{10}$, Florian Schütz ${ }^{11}$, Peter A. Fasching ${ }^{5}$, Tanja N. Fehm ${ }^{12}$, Hans-Christian Kolberg ${ }^{13}$, Johannes Ett| ${ }^{14}$

Affiliations

1 Department of Gynecology and Obstetrics, Ulm University Hospital, Ulm, Germany

2 National Center for Tumor Diseases, Division Gynecologic Oncology, University Hospital Heidelberg, Heidelberg, Germany

3 Department of Gynecology, Hamburg-Eppendorf University Medical Center, Hamburg, Germany

4 Department of Gynecology and Obstetrics, University Hospital Würzburg, Würzburg, Germany

5 Erlangen University Hospital, Department of Gynecology and Obstetrics, Comprehensive Cancer Center ErlangenEMN, Friedrich-Alexander University Erlangen-Nuremberg, Erlangen, Germany

6 Department of Obstetrics and Gynecology, University of Tübingen, Tübingen, Germany

7 Oncology Practice at Bethanien Hospital Frankfurt, Frankfurt, Germany

8 OncoConsult Hamburg GmbH, Hamburg, Germany

9 Charité University Hospital, Campus Benjamin Franklin, Department of Hematology, Oncology and Tumour Immunology, Berlin, Germany

10 ClinSol GmbH \& Co KG, Würzburg, Germany

11 Department of Obstetrics and Gynecology, University of Heidelberg, Heidelberg, Germany

12 Department of Gynecology and Obstetrics, University Hospital Düsseldorf, Düsseldorf, Germany

13 Department of Gynecology and Obstetrics, Marienhospital Bottrop, Bottrop, Germany

14 Department of Obstetrics and Gynecology, Klinikum rechts der Isar, Technical University of Munich, Munich, Germany
Key words

breast cancer, metastatic, advanced, PI3K, PD-L1, alpelisib, atezolizumab, PARP, supportive therapy

Schlüsselwörter

Mammakarzinom, Metastasen, fortgeschritten, PI3K, PD-L1, Alpelisib, Atezolizumab, PARP, Supportivtherapie

received 13.1.2019

accepted 28.1.2019

Bibliography

DOI https://doi.org/10.1055/a-0842-6661

Geburtsh Frauenheilk 2019; 79: 268-280 @ Georg Thieme

Verlag KG Stuttgart · New York | ISSN 0016-5751

Correspondence

Peter A. Fasching, MD

Erlangen University Hospital, Department of Gynecology and Obstetrics, Comprehensive Cancer Center Erlangen EMN, Friedrich Alexander University of Erlangen-Nuremberg Universitätsstraße 21-23, 91054 Erlangen, Germany peter.fasching@uk-erlangen.de

丹 Deutsche Version unter:

https://doi.org/10.1055/a-0842-6661

\section{ABSTRACT}

The treatment of patients with advanced breast cancer has developed further in recent years. In addition to therapeutic progress in the established subgroups (hormone receptor and HER2 status), there are now therapies which are geared to individual molecular characteristics, such as PARP inhibitor therapy in BRCA-mutated patients. In addition to this, tests are being developed which are intended to establish addition- 
al markers within subgroups in order to predict the efficacy of a therapy. PI3K mutation testing in HER2-negative, hormonereceptor-positive tumours and PD-L1 testing of immune cells in triple-negative tumours are expected to become established in clinical practice in order to select patients for the respective therapies. With new therapeutic approaches, new adverse effects also appear. The management of these adverse effects, just as those of classical therapy (supportive therapy), is essential with the introduction of new treatments in order to preserve patients' quality of life. Knowledge regarding measures to preserve and improve quality of life has significantly increased in recent years. Lifestyle factors should be taken into account, as should modern therapeutic methods. This review summarises the latest studies and publications and evaluates them in regard to the relevance for clinical practice.

\section{ZUSAMMENFASSUNG}

Die Behandlung von Patientinnen mit fortgeschrittenem Mammakarzinom hat sich in den letzten Jahren weiterentwickelt. Zusätzlich zum Therapiefortschritt in den etablierten Subgruppen (Hormonrezeptor- und HER2-Status) gibt es nun
Therapien, die sich an einzelnen molekularen Charakteristika orientieren, wie zum Beispiel die PARP-Inhibitortherapie bei BRCA-mutierten Patientinnen. Zusätzlich dazu sind Tests in der Entwicklung, die innerhalb von Subgruppen weitere Marker etablieren sollen, um die Wirksamkeit einer Therapie vorherzusagen. Die PI3K-Mutationstestung bei HER2-negativen, hormonrezeptorpositiven Tumoren, und die PD-L1-Testung von Immunzellen bei triple-negativen Tumoren werden voraussichtlich in der klinischen Praxis etabliert, um Patientinnen für die jeweiligen Therapien auszuwählen. Mit neuen Therapieansätzen treten auch neue Nebenwirkungen auf. Das Management dieser Nebenwirkungen ebenso wie die der klassischen Therapien (supportive Therapie) ist mit der Einführung neuer Behandlungen essenziell, um die Lebensqualität der Patientinnen zu erhalten. Das Wissen über Maßnahmen zur Erhaltung und Verbesserung der Lebensqualität hat in den letzten Jahren deutlich zugenommen. Lifestyle-Faktoren sollten dabei ebenso Berücksichtigung finden wie moderne Therapieverfahren. Diese Übersichtsarbeit fasst die neuesten Studien und Veröffentlichungen zusammen und bewertet sie in Bezug auf die Relevanz für die klinische Praxis.

\section{Introduction}

In the era of individualisation of therapies [1-4], additional targeted and immuno-oncological substances for defined groups of patients with advanced breast cancer are currently reaching the point of being ready for approval. The use of CDK4/6 inhibitors in HER2-negative and hormone-receptor-positive advanced breast cancer patients is standard. The approval of PARP inhibitors in $B R C A$-mutated patients is on the horizon. New studies on the efficacy of PI3K inhibitors in PI3K-mutated tumours were also presented, as were studies on the specific efficacy of checkpoint inhibitors. Thus the individualisation of therapy in clinical practice, which has been sought after for many years, appears to have been reached [5]. The following review presents the latest studies and publications from this context.

\section{Therapy for Metastatic Triple-Negative Breast Cancer}

The patient with metastatic triple-negative breast cancer (TNBC) continues to remain the major challenge in oncology. The classical therapeutic approach is chemotherapy. However, this option is associated with a short progression-free time (PFT); in the second line, the PFT is only nine weeks and only $49 \%$ of patients reach the third line [6]. The overall survival is approx. 13-14 months following diagnosis of metastasis.

Whereas in the past, therapy was performed analogously to non-triple-negative breast cancer, the Breast Committee of the German Gynaecological Oncology Working Group (AGO e. V.) currently recommends the use of therapies containing platinum for this group [7]. Future approaches may differentiate TNBC into a highly proliferative subtype which still requires chemotherapy, a subtype with detectable androgen receptor expression (possible anti-androgen therapy), a BRCA-associated type (use of PARP inhibitors) and an immuno-associated subtype which is characterised by immune infiltrates and which makes the use of checkpoint inhibitors appear promising [8]. After several phase II studies yielded the proof-of-concept, the results of the IMpassion130 study were recently published [8]. In this blinded phase III study, 451 patients with a non-pretreated metastasised TNBC were randomised $1: 1$ in each case to nab-paclitaxel $100 \mathrm{mg} / \mathrm{m}^{2}, \mathrm{~d} 1,8,15$, q28d, or the combination of nab-paclitaxel and the PD-L1 inhibitor atezolizumab. In addition to the previous therapy containing taxane and the presence of liver metastases, the PD-L1 status on the immune cells (IC, positive at $\geq 1 \%$ ) was the most important stratification factor. In the intention-to-treat (ITT) analysis, the PFT after a median follow-up of 12.9 months in the experimental arm was 7.2 vs. 5.5 months in the standard arm (HR $0.80[95 \% \mathrm{Cl}$ $0.69-0.92$ ]; $p=0.0025$ ). The overall survival, with an HR of 0.83 (95\% Cl 0.69-1.02) and a difference of 21.3 to 17.6 months, still did not achieve any statistical significance $(p=0.0840)$. Even if it was not envisaged by the statistical plan, the overall survival (OS) of the patients with a PD-L1-IC-positive tumour was descriptively assessed. This revealed a significant difference for this subgroup of 15.5 to 25.0 months (HR 0.62 [95\% Cl 0.45-0.86]) - for this challenging collective, this is a promising and practice-changing result, if the survival advantage should be confirmed in the final analysis. Yet many questions which were recently answered in the presentation of additional subgroup analyses still remain [9]. With regard to the PD-L1 status, the rationale of taking the positivity of the surrounding immune cells into account was based on the fact that triple-negative tumour cells rarely have PD-L1 expression; in the present study, only $9 \%$ of the tumour cells vs. 
$41 \%$ when immune cells are taken into account. That the PD-L1-IC status is essential for the response was confirmed by the negative results of the PD-L1-IC negative subgroup - the PFT in the standard as well as the experimental arm was 5.6 months $(p=0.5152)$ and the OS at 18.9 vs. 18.4 months $(p=0.9068)$. Other biomarkers such as CD8 positivity or the presence of stromal tumour-infiltrating lymphocytes (TiLs) were only predictive for a clinical benefit, even if there was also PD-L1-IC positivity. With the upcoming introduction of the PARP inhibitors, the question additionally arises about the extent to which atezolizumab is also effective if there is a BRCA mutation. If a BRCA mutation is present, the effectiveness was defined only by the PD-L1 status. PD-L1-IC-negative mutation carriers do not have any advantage through Atezolizumab for either PFT and OS, while for PD-L1-ICpositive mutation carriers, a benefit was able to be demonstrated for the PFT in particular (HR 0.45 [95\% Cl 0.21-0.96]; $p=0.04$ ). Accordingly, the combination therapy with checkpoint inhibitor for the subgroup of the PD-L1-IC-positive patients, independent of other biomarkers, should soon develop into the new standard in the first-line situation.

The situation shows that molecular diagnostics will increase in the case of patients with metastatic breast cancer. On the one hand, testing of immune cells for PD-L1 will become necessary in the case of triple-negative breast cancers. In the Impassion 130 study, approx. $40 \%$ of the patients were positive for this biomarker, just as in the case of testing for BRCA1 and BRCA2 in HER2negative breast cancers. In triple-negative breast cancers, a mutation could be found here in $10-20 \%$ of cases [10-15]. Therapeutic sequences have still not been established, however the prolongation of the OS argues in favour of primary therapy with the PD-L1 antibody.

\section{Therapy of Metastatic, Hormone-Receptor- Positive, HER2-negative Breast Cancer}

In the past 10 years, certain substances have been tested and also to some extent introduced into clinical practice with great success which, in the case of a combination with an antihormonal therapy, overcome endocrine resistance in some patients or improve the efficacy of the antihormonal therapy and thus lead to a longer PFT. After the introduction of everolimus $[16,17]$, it was able to be shown in seven studies that the CDK4/6 inhibitors (palbociclib, ribociclib and abemaciclib) prolong the PFT in pre- and postmenopausal patients and in several therapy lines, with hazard ratios between 0.5 and 0.6 (summarised in [18]). In addition to an improved PFT, a trend for a better OS was also reported by one of the studies [19]. It was also able to be shown that the quality of life could be improved by delaying progression [20,21].

Since therapy with a CDK4/6 inhibitor has become established as a standard in first-line therapy just one year after it became available [22], the question arises as to how these patients should continue to be treated in the event of discontinuation of the CDK4/6 inhibitor therapy. Despite the recommendation of fully utilizing anti-endocrine therapy, a sequence of multiple chemotherapies was used in a large portion of the patients [23]. This could be further improved by additional, effective combination therapies in the direction of more frequent anti-endocrine therapy. About $40 \%$ of hormone-receptor-positive HER2-negative breast cancers have mutations in the PI3K gene which is the most common genetic aberration in this tumour type [24,25]. The mutations can lead to tumour cell growth and endocrine resistance. For combination therapy with CDK4/6 inhibitors, it was further described that mutations such as the PI3K mutation newly accumulate in more than $8 \%$ of patients [26]. For this reason, therapy with a PI3K inhibitor would be entirely reasonable. Data from a prospectively randomised phase III study (SOLAR-1) on the PI3K inhibitor alpelisib were recently presented $[27,28]$. Alpelisib is a specific inhibitor of the PIK3CA isoform and specifically inhibits the mutated subunit. In the SOLAR- 1 study, 572 patients with advanced hormone-receptor-positive, HER2-negative breast cancer were divided in 2 cohorts, those with and without a PIK3CA mutation. Most of the patients were postmenopausal and all had received previous therapy with an aromatase inhibitor and approx. $10 \%$ with a CDK4/6 inhibitor. The mutation analysis was performed in primary tissue [27] for the primary analysis and in a secondary retrospective examination in circulating tumour DNA in the plasma (liquid biopsy) [28].

The patients were randomised in both cohorts in two treatment arms: fulvestrant plus alpelisib vs. fulvestrant plus placebo. About half of the patients had visceral metastases. The study reached its primary endpoint: The combination of alpelisib + fulvestrant prolonged the PFT of the PIK3CA-mutated patients from 5.7 to 11 months versus the control arm (HR 0.65; $95 \% \mathrm{Cl}: 0.50$ $0.85 ; p=0.00065)$. By contrast, no significant advantage was seen for combination therapy in the non-mutated cohort. The subgroup analysis showed for the PIK3CA-mutated patients a consistent advantage for the combination therapy. At the time of the first interim analysis, the results in overall survival were, by contrast, not yet mature.

Overall, the combination therapy was relatively well tolerated in comparison to other PI3K inhibitors investigated to date. The main adverse effect was hyperglycaemia at approx. 35\% (grade $3-4$ ) as well as skin toxicities (rash) with a frequency of $10 \%$ (grade 3-4). About two thirds of the mutated patients need treatment to be suspended or a dose reduction on the combination, and $25 \%$ discontinued treatment prematurely. The results of this biomarker-triggered study should lead to approval. However, the adverse effects are burdensome for the patients and necessitate special management. Likewise, the implementation of the PI3K mutation testing could be a challenge. Here it must be borne in mind that the testing can be performed on tumour material embedded in paraffin and also on ctDNA in blood. The analysis in which the patients were considered following a mutation documented on ctDNA showed similar efficacy, with a hazard ratio of $0.55[28]$.

\section{Therapy of Metastatic HER2-positive Breast Cancer}

The discovery of the amplification of HER2 with an unfavourable prognosis associated with it [29] and the subsequent development of the antibody trastuzumab [30,31] have significantly 


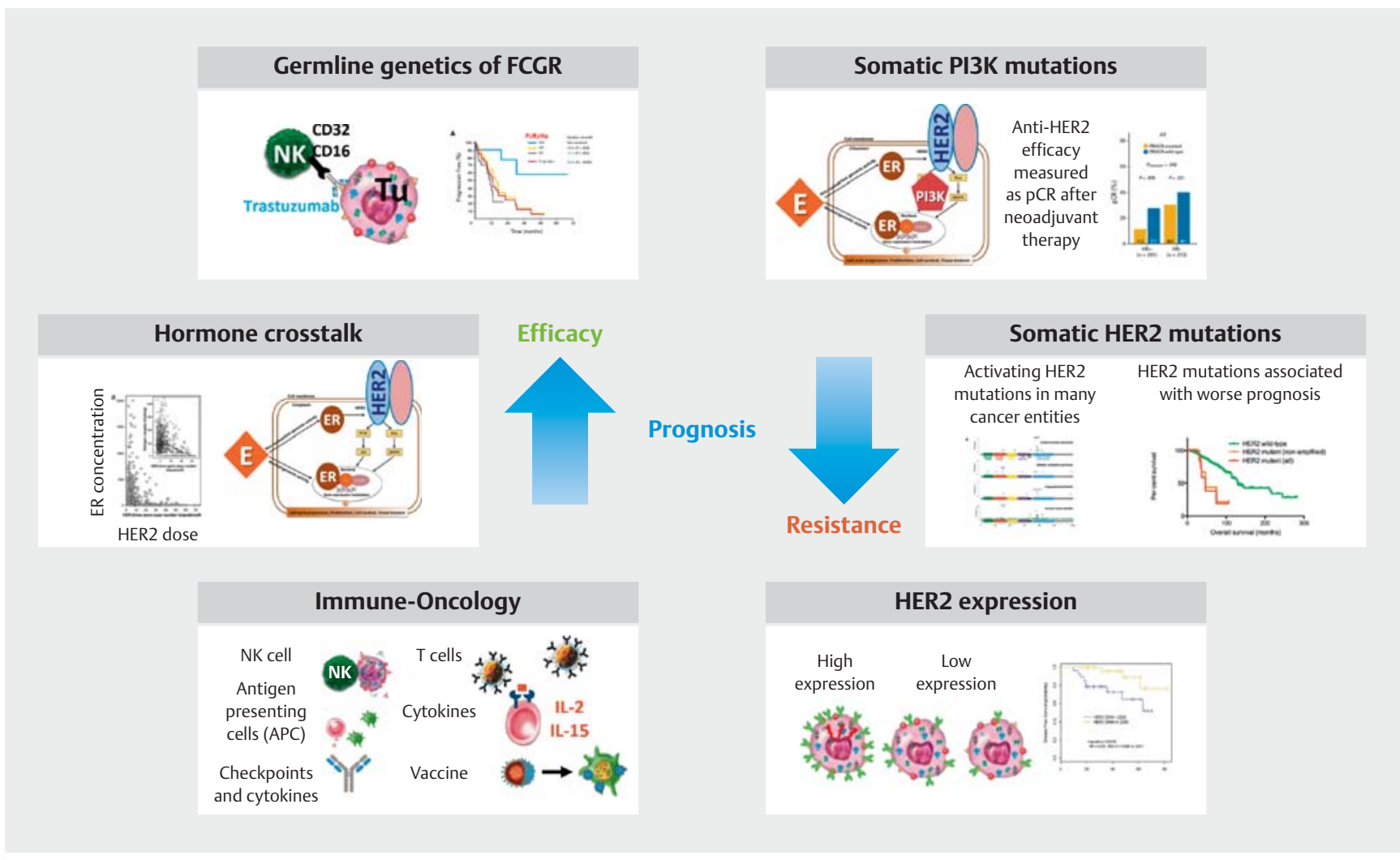

- Fig. 1 Reference mechanisms in anti-HER2 therapy (NK: Natural Killer Cell, Tu: Tumor, E: estrogen, ER: estrogen receptor; modified according to: $[32-37])$.

changed the treatment of patients with HER2-positive, advanced breast cancer in the past nearly 20 years. The introduction of the substances pertuzumab and trastuzumab emtansine (T-DM1) have been able to overcome some of the resistance mechanisms [32-37] ( $\triangleright$ Fig. 1) and achieve a significant prolongation in PFT and also OS [38-41], which has led to implementation in national and international guidelines [42]. A recently published work from the PRAEGNANT network [43] demonstrates the introduction of these therapies in "real world" clinical practice [44]. This work was able to show that more than $80 \%$ of all HER2-positive patients had received trastuzumab until the 4 th line of therapy, about $70 \%$ received the combination of trastuzumab and pertuzumab, approx. $50 \%$ lapatinib and also about 50\% T-DM1 [44]. The sequence of trastuzumab + pertuzumab followed by T-DM1 was given to about $40 \%$ of the patients until the 4 th line of therapy. Patients with a negative hormone receptor status or a high grading appear to have received this sequence more often [44].

The antibody drug conjugate (ADC) T-DM1 represents the introduction of an effective therapy with a novel effect. DS-8201a is another ADC which is currently being tested in clinical studies. The chemotherapeutic agent (DXd, a topoisomerase-I inhibitor) is bound with a linker to trastuzumab which releases the chemotherapeutic agent after binding to the HER2 molecule $[45,46]$. The molecule is deemed to be effective even in patients with low HER2 expression. This could also be shown in a very large phase I study [47]. However, in the case of just over 240 treated patients, there was death associated with pneumonitis. The reappraisal of the cases concludes that therapy, when this serious adverse effect is taken into account, is possible with intensive monitoring, stopping the medication with DS-8201a upon appearance and treatment with corticosteroids [48]. At present, this substance is being tested after T-DM1 in a phase II study on patients with HER2 overexpression (NCT03523585).

The therapy sequence pertuzumab + trastuzumab $\rightarrow$ T-DM1 is supported by the guidelines, however pertuzumab and T-DM1 were developed simultaneously in clinical studies and thus no patients who were pretreated with pertuzumab had participated in the EMILIA study [41]. The median PFT was 9.6 months [41]. Data on the median PFT have now also been published from the PRAEGNANT network. For patients who had received T-DM1 after pertuzumab, the PFT times were 7.7, 4.2 and 4.0 months for patients in the 2nd, 3rd and 4th line of therapy [49]. However it must be noted that the number of cases -57 patients - was small.

\section{The Special Metastatic Situation - Brain Metastases}

Improvement in the treatment options of patients with metastatic breast cancer has led to prolonged survival. With improved monitoring of metastatic spread, about $30 \%$ of all patients with metastases develop brain metastases in the course of their disease. 
Brain metastases often represent the limiting factor of the disease, since survival after the occurrence of brain metastases is generally only a few months. In addition to the poor prognosis, there is a massive limitation in quality of life due to cognitive and neurological deficits. Patients with HER2-positive or triple-negative carcinomas develop brain metastases more frequently. A recently presented investigation addressed the incidence of cerebral metastases as the first site of metastasis following adjuvant therapy in patients with HER2-positive breast cancer. The followup of the patients from the BCIRG-006 study which investigated the use of trastuzumab in the adjuvant therapy of breast cancer was analysed for this purpose [30]. Of the 3222 patients, $17.8 \%$ developed distant metastasis in the case of a median follow-up period of 10.3 years. In $17.5 \%(n=101)$ of these distant metastases, brain metastases were the first location of the metastasis. No difference in the frequency with and without trastuzumab could be observed. A negative hormone receptor status and more than 3 affected axillary lymph nodes could be identified as risk factors for the development of cerebral metastases. Overall, however, very little is known regarding the therapy and prognosis of patients with brain metastases who were treated outside of clinical studies. To improve the data in this regard, the registry "Brain Metastases in Breast Cancer (BMBC)" was initiated to document the actual German care situation. Along with an analysis on the outcome of about 1700 patients treated in Germany [50] which has already been published, another assessment was currently presented. Here, a prognosis score which was already published, the "breast-graded prognostic assessment (GPA)" [51], was validated in the German cohort [52]. This score is based on the factors of Karnofsky status, biological subtype of the tumour and age of the patient. The assessment of patients' prognosis is relevant in routine clinical practice, for example, for decisions regarding the radical nature of therapeutic measures. The median survival in the subgroups varied in the German cohort between 2.4 and 12.3 months. In this case, the score was able to differentiate well between various prognosis groups, however the survival time was shorter than in the published cohort from Sperduto et al., which was between 3.4 and 25.3 months. This underscores the fact that there can by all means be differences in the absolute survival in various clinical cohorts. Even more unfavourable than the survival of patients with brain metastases is the prognosis of patients with involvement of the meninges (Meningeosis carcinomatosa). As in the case of cerebral metastases, data are also lacking here on options for systemic therapy. In a small cohort of 7 patients with hormone-receptor-positive and HER2-negative breast cancer, data on the efficacy of the CDK4/6 inhibitor abemaciclib were presented [53]. A therapeutic response in individual patients as well as an overall survival of 8.4 months could be observed; this is longer than in comparative cohorts. The study is currently being continued.

In summary, the problem of cerebral metastasis is increasingly becoming the focus of research efforts which will hopefully contribute to improving the treatment in the foreseeable future.

\section{CTCs and DTCs as Biomarkers in Breast Cancer}

The prognostic value of disseminated tumour cells (DTC) from the bone marrow and circulating tumour cells (CTC) from the blood has already been demonstrated in several works [54-61] and there is a greater amount of data for CTCs for DTCs. In spite of everything, disseminated tumour cells are of particular relevance. It was recently shown that, as part of the carcinogenesis of breast cancer, individual cells leave the primary lesions very early on and are responsible for metastatic recurrence [62]. Within the scope of a large pooled analysis, Hartkopf et al. confirm the prognostic relevance of DTCs in 10307 patients with early breast cancer [63]. In $27.3 \%$ of all patients, tumour cells were detected in the bone marrow at the time of primary diagnosis and the detection was associated with a significantly worse OR (HR: 1.23, $p=0.006)$ and disease-free survival (DFS) (HR: 1.30; $p<0.001$ ). It was also shown that, above all, DTC-positive patients with luminal B tumours (defined as HR+/HER2-/G3) have a greater risk of distant metastasis (HR: 2.34). Whether the determination of DTCs can be used as a prediction marker for adjuvant therapeutic strategies, e.g. a treatment with bisphosphonates, is currently being investigated within the scope of prospective studies (e.g. NCT01545648).

In patients with metastatic breast cancer, the detection of at least 5 circulating tumour cells (CTC) in peripheral venous blood is a negative prognostic factor [64]. Bidard et al. therefore posted the question of whether the detection of CTCs (at least 5 CTCs/ $7.5 \mathrm{ml}$ blood using CellSearch, Menarini Silicon Biosystems, Castel Maggiore BO, Italy) in patients with hormone-receptor-positive, HER2-negative breast cancer at an advanced stage can be used as a decision-making criterion as to whether endocrine therapy (ET) is sufficient or chemotherapy with subsequent endocrine therapy (CTX) is necessary [65]. For this purpose, 761 patients were included in the prospectively randomised phase III STIC CTC study. A 1:1 randomisation was performed. In the standard arm, treatment was administered at the discretion of the attending physician (ET or CTX). In the CTC arm, ET was used if there were $<5$ CTCS and CTX was used if there were $\geq 5$ CTCs. The primary endpoint was the comparison of the progression-free survival of both arms. Here, the CTC arm was not inferior to the control arm. In a planned subgroup analysis, it was additionally shown that patients with $\geq 5$ CTCs also benefit from chemotherapy if endocrine therapy was considered to be sufficient from a clinical viewpoint [65]. The authors thus conclude that CTCs could be used as a marker for the use of chemotherapy. However, two questions remained unanswered. On the one hand, it should be clarified in further studies how the study results can be integrated into clinical practice in the era of CDK4/6 inhibition. On the other hand, it is unclear whether more intensive treatment can be eliminated in the case of patients with $<5$ CTCs. For this reason, the results of the STIC CTC study are especially important because it was shown for the first time in a prospectively randomised situation that certain patients with hormone-receptor-positive, HER2negative, advanced breast cancer benefit from chemotherapy (at least in comparison to a purely endocrine treatment). 


\section{Supportive Therapy}

Supportive therapy is a fundamental but also complex part of the oncological therapy and care which calls for a high degree of interdisciplinary collaboration and a trusting relationship between the patient and physician. Various guideline committees and expert panels have attempted to summarise the challenges and the resultant recommendations $[7,66-70]$. An overview of the treatment fields and necessary considerations is presented in $>$ Table 1. For most of the relevant, clinically significant adverse effects, there are working groups which are developing treatment regimens [71-78]. For practical use, digitised applications as shown in > Fig. 2 have been developed. While studies for new oncological therapies are often conducted with many resources, specific supportive therapies only develop afterwards and the knowledge about avoiding short- and long-term toxicities often follows only years after widespread use of the drugs. Some current studies are mentioned below.

\section{Anthracycline-induced cardiotoxicity: no reliable medical prevention}

The significance of cardiotoxicity of therapy containing anthracyclines often only becomes clear in long-term investigations. In a 10-year investigation comparing three therapies (chemo containing anthracycline $[A]$ vs. A + trastuzumab $[T]$ vs. anthracycline-free chemo + trastuzumab), five times as many cardiac deaths were found in the $A+T$ arm than in the anthracycline-free arm in the 10-year follow-up period [79]. While the option of anthracyclinefree therapy is established in HER2-positive patients, there is a smaller amount of data regarding HER2-negative breast cancer,

- Table 1 Examples of supportive measures (modified according to $[7,66-68,70]$ ).

\begin{tabular}{|c|c|c|}
\hline Supportive measure & Basic & Further \\
\hline Patient information & $\begin{array}{l}\text { Information on the disease, therapy, } \\
\text { adverse effects and self-help groups }\end{array}$ & Events for patients and family members \\
\hline Information for family members & $\begin{array}{l}\text { Information on the disease, therapy, } \\
\text { adverse effects and self-help groups }\end{array}$ & Events for patients and family members \\
\hline Physician information & $\begin{array}{l}\text { Continuous information and further training } \\
\text { in new and complex therapies }\end{array}$ & $\begin{array}{l}\text { Establishment of multidisciplinary treatment } \\
\text { of adverse effects for special therapies }\end{array}$ \\
\hline Psycho-oncology & Provision of psycho-oncological care & Events for patients and family members \\
\hline Pastoral care & Provision of pastoral care & Events for patients and family members \\
\hline Musculoskeletal measures & Counselling on physical, functional activity & Physical therapy, drug therapy \\
\hline Nutrition and digestion & $\begin{array}{l}\text { In the case of some therapies: peristalsis inhibitors } \\
\text { (e.g. loperamide), if necessary, infectious disease } \\
\text { diagnostic testing }\end{array}$ & $\begin{array}{l}\text { If needed: peristalsis inhibitors, anti-constipation } \\
\text { therapy, infectious disease diagnostic testing, } \\
\text { dietary consultation }\end{array}$ \\
\hline Stomatitis & Counselling on nutrition, food intake & Topical therapy \\
\hline Nausea and vomiting & $\begin{array}{l}\text { Antiemetics according to guideline } \\
\text { (incl. steroids, HT3-i and NK1-i) }\end{array}$ & Behavioural therapy, psycho-oncological support \\
\hline Adverse dermatological effects & Information & Topical therapy \\
\hline Infusion damage & Information & DMSO, dexrazoxane, surgical therapy \\
\hline Neurotoxicity & Information, pain therapy, physical therapy & Drug therapy \\
\hline Cardiotoxicity, rhythm & $\begin{array}{l}\text { Information and knowledge about cardiotoxic } \\
\text { substances, monitoring of heart function } \\
\text { (LVEF, QTc time) }\end{array}$ & \\
\hline Myelosuppression & $\begin{array}{l}\text { Monitoring of blood values, knowledge about } \\
\text { therapies which require primary prophylaxis }\end{array}$ & $\begin{array}{l}\text { Colony-stimulating factors, erythropoietin, } \\
\text { transfusions }\end{array}$ \\
\hline Infections & Hepatitis B screening, anti-infectious therapy & Reserve therapeutic agents \\
\hline Fatigue & Information & Psychosocial support \\
\hline Sleep disorders & Information & Behavioural therapy \\
\hline Pain & Tiered pain therapy, physical therapy & Pain specialist \\
\hline Fertility & $\begin{array}{l}\text { Contraception during therapy, effects of therapy } \\
\text { on fertility }\end{array}$ & Cryopreservation, medical preservation of fertility \\
\hline Menopausal symptoms & Information on the effects of therapy & Symptomatic therapy \\
\hline Bone health & $\begin{array}{l}\text { Bisphosphonates, denosumab, physical exercise, } \\
\text { nutritional counselling }\end{array}$ & \\
\hline Lifestyle & Counselling & \\
\hline Long-term complications & Information, programmed aftercare & Symptom-oriented therapy \\
\hline
\end{tabular}




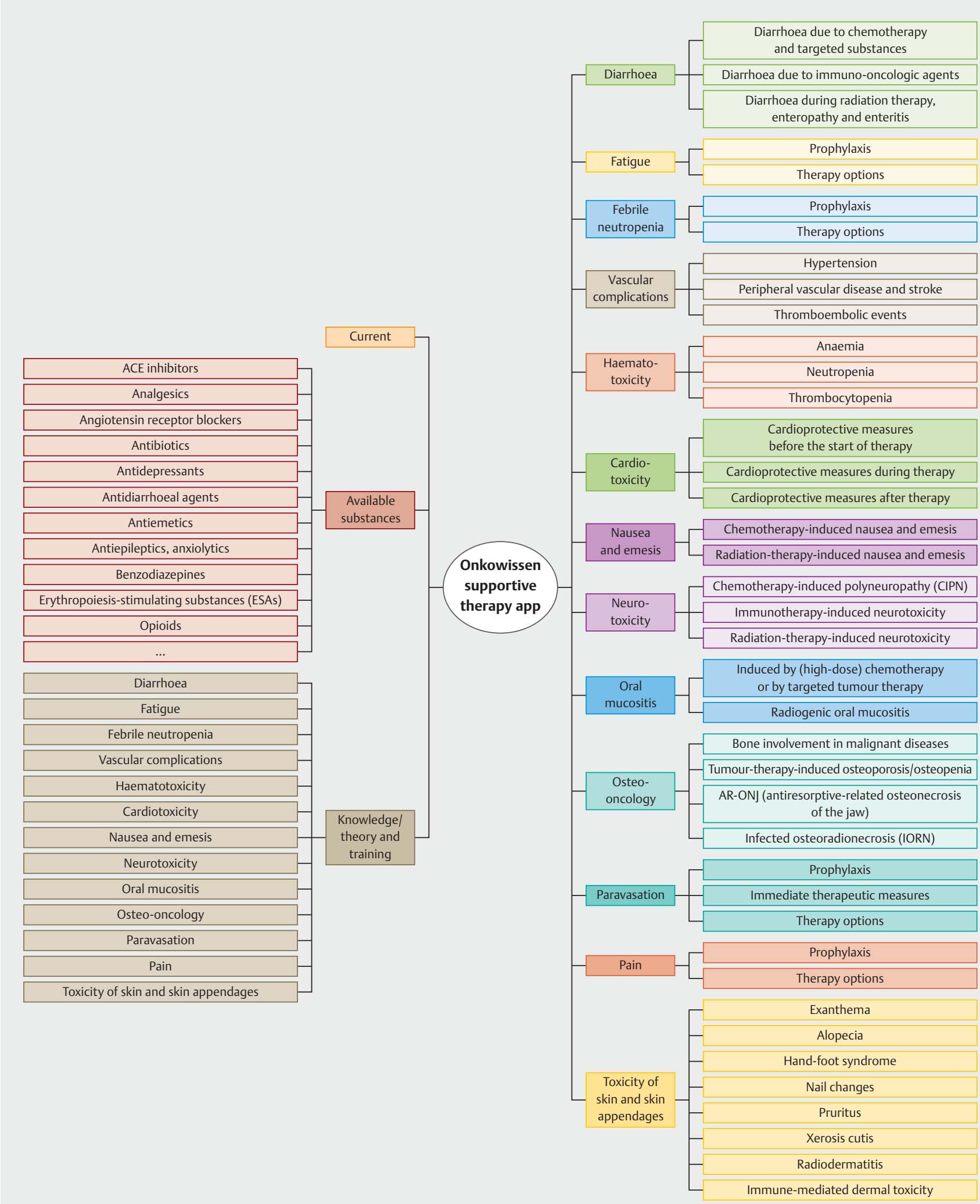

- Fig. 2 Supportive measures as described in the application of www.onkowissen.de. 
though there are indications that anthracycline-free therapy is similarly effective [80]. However, if patients are prescribed therapy containing anthracycline, the question of possible prevention during the therapy arises. One of the largest studies to date was recently published regarding this topic [81]. It was investigated whether anthracycline-induced cardiotoxicity can be reduced by an ACE-inhibitor or a $\beta$-blocker. The study investigated 468 patients with primary HER2-positive breast cancer who received adjuvant therapy with trastuzumab. The chemotherapy administered previously could be anthracycline-based or anthracyclinefree. Beta blockers (carvedilol) vs. ACE inhibitors (lisinopril) vs. placebo were investigated in the 3-arm study. The primary endpoints were defined as: Decrease in the ejection fraction (EF) by at least 10 or $5 \%$ and a decrease below the threshold of $<50 \%$. The observation period was 2 years. The patients were stratified according to therapy containing anthracyclines and anthracycline-free therapy.

There were no differences in the anthracycline-free cohort. In the cohort with anthracycline, it was shown that the cardiotoxicity was able to be reduced by the ACE inhibitor (37\%) as well as by the $\beta$-blocker (31\%). However, $47 \%$ also had cardiotoxicity in the placebo arm.

Thus the potential use of cardiac medications for cardioprotection was confirmed by the study, but the result of the study is unsatisfactory in view of the results in the control arm. EF as a surrogate marker may be an inadequate parameter for the primary endpoint. The definition of manifest heart failure would have been more accurate and meaningful.

The fact that no reduced cardiotoxicity was observed in the anthracycline-free stratum reinforces the trend in the direction of anthracycline-free therapies.

\section{Hot flushes: Oxybutynin reduces the intensity and frequency}

Hot flushes are a topic which not only negatively impacts patients' quality of life but which may also have an effect on the prognosis. It is known that women with adverse effects have worse compliance (adherence) on antihormonal therapy [82,83]. In addition, it was able to be shown that reduced compliance can have an effect on the prognosis of postmenopausal, hormone-receptor-positive patients on aromatase inhibitor therapy [84]. Supportive medication could therefore be relevant in many ways, since hormone replacement is not indicated. One randomised, double-blind, placebo-controlled study investigated the anticholinergic oxybutynin, which is approved for the treatment of hyperactivity of the bladder muscles but which also appears effective against hot flushes. Oxybutynin was tested in the 3-arm study orally in two dosages ( $2.5 \mathrm{mg}$ and $5 \mathrm{mg}$ ) vs. placebo. The dose used here is significantly lower than the dose generally used in the treatment for an overactive bladder. Women with a high frequency of hot flushes were included. Most women were receiving therapy with tamoxifen or an aromatase inhibitor. The duration of treatment was 6 weeks following a baseline week without medication. The intensity and frequency of hot flushes were evaluated. The change in the weekly intensity and frequency of hot flushes was defined as a primary endpoint.
The intensity as well as the frequency of hot flushes were able to be significantly decreased $(p<0.01)$, independent of the dose of oxybutynin applied. The adverse effects were acceptable and primarily involved mouth dryness, urinary retention, dry eyes, diarrhoea and headaches. When compared to other substances used to combat hot flushes such as fluoxetine, citalopram or venlafaxin, oxybutynin performed significantly better. Since the study had observed a total of only 150 patients, it remains to be seen how the medication behaves in a larger population.

\section{Widespread use of antiemesis}

Antiemesis has developed in recent years into a highly effective supportive therapy. In the era prior to the introduction of the 5HT3 receptor antagonists, vomiting was usually reported in more than $60 \%$ of patients during standard chemotherapy for breast cancer patients [85]. Nowadays, these rates are significantly lower in routine clinical practice with the aid of prophylaxis with steroids, 5-HT3 receptor antagonists and neurokinin-1 (NK1) receptor antagonists, as recommended in current guidelines [75] and as described in a large study [86]. An analysis of nearly 1000 breast cancer patients ( $n=986$ ) who received standard chemotherapy and the combination preparation NEPA (netupitant + palonosetron) was able to show that vomiting occurred in only about $10 \%$ of the women and nausea in about $30-40 \%$ of the patients [86]. This emphasises the significant advancements in the supportive therapy of this adverse effect which still had a significant influence on patients' quality of life on chemotherapy just a few decades ago.

The use of antiemetics is largely predicated on the emetogenic risk of chemotherapy. The main predictor here is the type of chemotherapy. Individual factors can also be considered. Individual molecular predictors have still not been established, although promising results already exist [87-90]. The next steps here could also be the individualisation of the therapy.

\section{Lifestyle for Prevention, Improvement of the Prognosis and Support of Breast Cancer Therapy}

Many new approaches focus on the topic of "quality of life". This relates to the well-being of patients on various forms of therapy, the possible change due to certain behavioural rules as well as a quality-of-life measurement. While it is nearly self-evident for clinically experienced oncologists that adjuvant chemo- or antihormonal therapy, in comparison to purely endocrine treatment, leads to a (at least transient) worsening in quality of life, there has been a lack of randomised data on this subject to date. Quality-of-life data were collected in the TAILOR-X study [91] and these data were able to show a worsening in cognitive performance, fatigue and endocrine deficits in more than 10000 breast cancer patients, particularly in the interval from 3-6 months after the start of treatment [92]. In this respect, it makes clinical sense that other groups have set out to improve this "deep valley" of quality of life (and with limitations in the prognosis) under adjuvant chemotherapy through "lifestyle" interventions. 


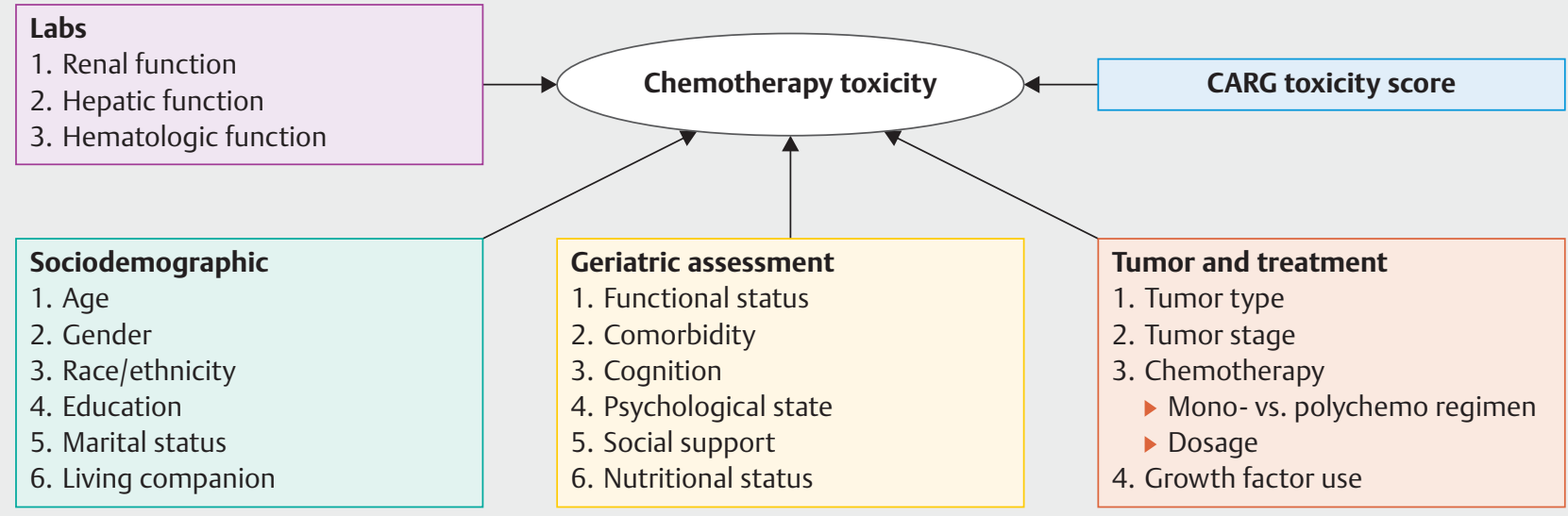

- Fig. 3 Composition and concept of the CARG (Cancer \& Aging Research Group) Toxicity Tools.

Two recently presented studies were able to demonstrate clinically feasible results through training in particular $[93,94]$. The Finnish study group working with the "EDDA" studies investigated whether a 12-month period of strength and endurance training on adjuvant chemotherapy can improve cardiopulmonary performance, demonstrated by the $\mathrm{VO}_{2} \max$ [94]. The training program was very challenging with a total of 4 hours of training per week, 2 of which were under the personal instruction of a physiotherapist; the control group received counselling, as is customary according to Norwegian standards. Adherence was at $70 \%$ during an observation period of one year. The most pronounced worsening in $\mathrm{VO}_{2}$ max was found in control patients receiving chemotherapy containing taxanes, with an average loss of $17 \%$ after 6 months and persistence of the decrease by $7.3 \%$ after 1 year, while the patients who performed exercise experienced a loss of only $1.4 \%$.

The German SUCCESS study group chose a similar approach, however using telephone counselling and mailings without personal trainer contact over the entire 2-year period [93]. The patient selection was also different, since only patients with a body mass index (BMI) of $24-40 \mathrm{~kg} / \mathrm{m}^{2}$ were included. Under advisory supervision, the patients lost $1 \mathrm{~kg}$ in body weight within 2 years, while the control patients gained $1 \mathrm{~kg}$. However, adherence in this investigation was only around $50 \%$. If only the so-called "completers" are considered, that is, the patients who were compliant during the 2-year observation period, a difference of more than $3 \mathrm{~kg}$ in body weight is seen between the two arms and a hazard ratio in favour of the intervention group of 0.51 in the multivariate analysis of disease-free survival [93]. All of these results greatly support the need for counselling, because the relative effect of weight reduction and exercise is as relevant as the effect of adjuvant chemotherapeutic or endocrine treatment.

Nonetheless, the difficult task of correctly assessing older patients' fitness for therapy remains. The CARG (Cancer \& Aging Research Group) Toxicity Tool which is composed of various parameters from the categories sociodemographic data, tumour and therapy details as well as laboratory parameters was developed for this purpose ( $\bullet$ Fig. 3) [95]. The score correlates very well with the high-grade toxicities and the need for dose reduction, therapy postponement and hospitalisation and thus represents an excellent aid for making decisions regarding the feasibility of adjuvant chemotherapy in older patients.

\section{Biomarkers and Genomic Characterisation}

While the establishment of molecular markers took a long time in the past [96], the challenge for the future is to put the abundance of biomarkers into a meaningful clinical context. One focus in the case of metastatic breast cancer is the description of the genomic characterisation and the detection of special mutations which occur within the scope of the metastasis or the progression or which contribute to it. It is known that, for example, under the pressure of endocrine therapy, ESR 1 mutations of the tumour cells can increasingly appear within the framework of metastasis [26]. To date, there is little evidence of other mutation patterns. As part of a more recent study [97], tumour material and blood serum from 629 patients with metastatic disease were analysed. The collective came from six French studies (SAFIR-01 [98], SHIVA [99], MOSCATO [100], SAFIR-02 (NCT02299999), PERMED-01 (NCT02342158), MATCH-R (NCT02517892). The objective was a "whole exome" sequencing of the tumour tissue and the serum DNA (HiSeq: $n=262$ /Novaseq: $n=367$ ) for the identification of genomic patterns and the comparison between early $(e B C)$ and metastatic ( $\mathrm{mBC}$ ) breast cancer. The tumour biology of the $629 \mathrm{mBC}$ patients demonstrated the following distribution: $n=387:$ HR+/HER2-, $n=186:$ TNBC, $n=32$ : HER2+. Most of the biopsies were taken from the liver ( 272 patients $=43.2 \%$ ) and to a lesser extent from lymph nodes (111 patients $=17.6 \%$ ) or other metastatic locations. Overall a high degree of heterogeneity and clonal diversity between the mutation patterns which dramatically increase within the scope of metastasis in relation to the early disease was seen. However, this primarily concerned HR+/HER2$\mathrm{mBC}$, while in the case of TNBC, there was greater diversity within the scope of early disease. In the overall collective, nine driver mutations (TP53, NF1, RB1, RBMX, FRG1, ESR1, RIC8A, AKT1, KRAS) were primarily seen which increasingly appeared in $\mathrm{mBC}$ patients 
in relation to $\mathrm{eBC}$ patients and which are to some extent associated with a worse outcome. These could be detected in patients with $\mathrm{HR}+/ \mathrm{HER} 2-\mathrm{mBC}$, however not in the case of HER2+ $\mathrm{mBC}$ or mTNBC. Mutations which should be considered to be therapeutic targets (PIC3CA, BRCA2) could be detected significantly more frequently in the case of HR+/HER2- $\mathrm{mBC}$ than in HER2+ $\mathrm{mBC}$ or mTNBC. Three mutation signatures (S13 [APOBEC], S10 [POLE], $S 17$ [no name]) were detected more frequently in metastatic tissue in comparison to early breast cancer. These are considered to be a surrogate of "genomic evolution" and the detection of these signatures was also associated with a worse outcome, particularly if these occurred in combination. These signatures could also be detected in the case of HR+/HER2- $\mathrm{MBC}$, while no signatures could be derived in the case of mTNBC due to enormous heterogeneity. Interestingly, however, a subgroup of the mTNBC patients demonstrated somatic biallelic loss-of-function mutations (LoF) on genes which code for hormone receptor cascades and which could thus represent a population for therapy with PARP inhibitors. If the frequency of germ line mutations of BRCA1 and $B R C A 2$ and, if applicable, other homologous repair genes such as CHEK2, ATM, BARD1, PALB2 and RAD51D [10,11, 101, 102] are taken into account, the total percentage of patients who are considered for PARP inhibitor therapy could be more than $10 \%$ of all breast cancer patients. However, this still needs to be proven in studies.

The structuring of the introduction of such multi-genomic approaches requires structured, possibly computer-aided management. The support of the physician through systems which may be supported by machine learning could be an approach for introducing these big-data analyses in clinical practice $[103,104]$.

\section{Outlook}

Even if all studies and results described have significant scientific benefits, the direct clinical challenges are clear. The implementation of BRCA testing of all HER2-negative advanced breast cancer patients, the PI3K mutation testing of HER2-negative, hormonereceptor-positive patients and the therapy management in antiPD1/PD-L1 therapies and anti-PI3K therapies appear to be the main tasks of the next few months in order to be optimally prepared for upcoming therapies.

\section{Acknowledgements}

This work was developed in part as a result of support from Riemser and the PRAEGNANT network which is supported by Hexal, Pfizer, Celgene, Daiichi-Sankyo, Roche, Merrimack, Eisai, and Novartis. None of the companies played a role in the drafting of this manuscript. The authors alone are responsible for the content of the manuscript.

\section{Conflict of Interest}

A.D. H. received speaker and consultancy honoraria from AstraZeneca, Genomic Health, Roche, Novartis, Celgene, Lilly, MSD, Eisai, Teva, Tesaro, Daiichi-Sankyo, Hexal and Pfizer. N. N. received consultancy honoraria from Janssen-Cilag and Novartis. F.O. received speaker and consultancy honoraria from Amgen, AstraZeneca, Bayer, BMS, BoehringerIngelheim, Chugai, Celgene, Cellex, Eisai, Gilead, Hexal, Ipsen, Janssen-
Cilag, Merck, MSD, Novartis, Riemser, Roche, Tesaro and Teva. F.-A. T. received honoraria from Astra Zeneca, Genomic Health and Novartis. H.-C. K. received honoraria from Carl Zeiss meditec, Teva, Theraclion, Novartis, Amgen, Astra Zeneca, Pfizer, Janssen-Cilag, GSK, LIV Pharma, Roche and Genomic Health. P.A. F. received honoraria from Novartis, Pfizer, Roche, Amgen, Celgene, Daiichi-Sankyo, AstraZeneca, MerckSharp \& Dohme, Eisai, Puma and Teva. His institution conducts research with funding from Novartis and Biontech. H. T. received honoraria from Novartis, Roche, Celgene, Teva, Pfizer and travel support from Roche, Celgene and Pfizer. J. E. received honoraria from AstraZeneca, Roche, Celgene, Novartis, Lilly, Pfizer, Pierre Fabre, Teva and travel support from Celgene, Pfizer, Teva and Pierre Fabre. M.P. L. has participated on advisory boards for AstraZeneca, MSD, Novartis, Pfizer, Eisai, Genomic Health and Roche and has received honoraria for lectures from MSD, Lilly, Roche, Novartis, Pfizer, Genomic Health, AstraZeneca, medac and Eisai. V. M. received speaker honoraria from Amgen, Astra Zeneca, Celgene, Daiichi-Sankyo, Eisai, Pfizer, Novartis, Roche, Teva, Janssen-Cilag and consultancy honoraria from Genomic Health, Hexal, Roche, Pierre Fabre, Amgen, Novartis, MSD, Daiichi-Sankyo and Eisai, Lilly, Tesaro and Nektar. E. B. received honoraria from Novartis, Celgene, Riemser, Pfizer, Hexal, Amgen, and onkowissen.de for consulting, clinical research management or medical education activities. A.S. received honoraria from Roche, Celgene, AstraZeneca, Novartis, Pfizer, Zuckschwerdt Verlag $\mathrm{GmbH}$, Georg Thieme Verlag, Aurikamed GmbH, MCI Deutschland $\mathrm{GmbH}$, bsh medical communications $\mathrm{GmbH}$ and promedicis $\mathrm{GmbH}$. W. J. received honoraria and research grants from Novartis, Roche, Pfizer, Lilly, AstraZeneca, Chugai, Sanofi, Daichi and Tesaro. F. S. participated on advisory boards for Novartis, Lilly, Amgen and Roche and received honoraria for lectures from Roche, AstraZeneca, MSD, Novartis and Pfizer. A. W. participated on advisory boards for Novartis, Lilly, Amgen, Pfizer, Roche, Tesaro, Eisai and received honoraria for lectures from Novartis, Pfizer, Aurikamed, Roche, Celgene. D. L. received honoraria from Amgen, AstraZeneca, Celgene, Lilly, Loreal, MSD, Novartis, Pfizer, Tesaro and Teva T. N. F. has participated on advisory boards for Amgen, Daichi Sankyo, Novartis, Pfizer, and Roche and has received honoraria for lectures from Amgen, Celgene, Daichi Sankyo, Roche, Novartis and Pfizer.

\section{References}

[1] Taran FA, Schneeweiss A, Lux MP et al. Update Breast Cancer 2018 (Part 1) - Primary Breast Cancer and Biomarkers. Geburtsh Frauenheilk 2018; 78: 237-245

[2] Schneeweiss A, Lux MP, Janni W et al. Update Breast Cancer 2018 (Part 2) - Advanced Breast Cancer, Quality of Life and Prevention. Geburtsh Frauenheilk 2018; 78: 246-259

[3] Wockel A, Lux MP, Janni W et al. Update Breast Cancer 2018 (Part 3) Genomics, Individualized Medicine and Immune Therapies - in the Middle of a New Era: Prevention and Treatment Strategies for Early Breast Cancer. Geburtsh Frauenheilk 2018; 78: 1110-1118

[4] Muller V, Wockel A, Lux MP et al. Update Breast Cancer 2018 (Part 4) Genomics, Individualized Medicine and Immune Therapies - in the Middle of a New Era: Treatment Strategies for Advanced Breast Cancer. Geburtsh Frauenheilk 2018; 78: 1119-1128

[5] Fasching PA, Schneeweiss A, Kolberg HC et al. Translational highlights in breast cancer research and treatment: recent developments with clinical impact. Curr Opin Obstet Gynecol 2019; 31: 67-75

[6] Kassam F, Enright K, Dent R et al. Survival outcomes for patients with metastatic triple-negative breast cancer: implications for clinical practice and trial design. Clin Breast Cancer 2009; 9: 29-33

[7] Kommission Mamma der Arbeitsgemeinschaft Gynäkologische Onkologie e.V. in der Deutschen Gesellschaft für Gynäkologie und Geburtshilfe e.V. sowie in der Deutschen Krebsgesellschaft e.V. Diagnostik und Therapie von Patientinnen mit primärem und metastasiertem Brustkrebs. 2018. Online: https://www.ago-online.de/de/infothek-fueraerzte/leitlinienempfehlungen/mamma/; last access: 07.07.2018 
[8] Schmid P, Adams S, Rugo HS et al. Atezolizumab and Nab-Paclitaxel in Advanced Triple-Negative Breast Cancer. N Engl J Med 2018; 379: 2108-2121

[9] Emens LA, Loi S, Rugo HS et al. IMpassion130: Efficacy in immune biomarker subgroups from the global, randomized, double-blind, placebocontrolled, phase III study of atezolizumab + nab-paclitaxel in patients with treatment-nave, locally advanced or metastatic triple-negative breast cancer. San Antonio Breast Cancer Symposium 2018; Abstr. GS104

[10] Couch F], Hart SN, Sharma P et al. Inherited mutations in 17 breast cancer susceptibility genes among a large triple-negative breast cancer cohort unselected for family history of breast cancer. J Clin Oncol 2015; 33: 304-311

[11] Fasching PA, Hu C, Hart SN et al. Cancer predisposition genes in metastatic breast cancer - Association with metastatic pattern, prognosis, patient and tumor characteristics [abstract]. In: Proceedings of the 2017 San Antonio Breast Cancer Symposium; 2017 Dec 5-9; San Antonio, TX Philadelphia (PA): AACR. Cancer Res 2018; 78: Abstr. PD1-02

[12] Fasching PA, Loibl S, Hu C et al. BRCA1/2 Mutations and Bevacizumab in the Neoadjuvant Treatment of Breast Cancer: Response and Prognosis Results in Patients With Triple-Negative Breast Cancer From the GeparQuinto Study. J Clin Oncol 2018. doi:10.1200/JCO.2017.77.2285

[13] Hahnen E, Lederer B, Hauke J et al. Germline Mutation Status, Pathological Complete Response, and Disease-Free Survival in Triple-Negative Breast Cancer: Secondary Analysis of the GeparSixto Randomized Clinical Trial. JAMA Oncol 2017; 3: 1378-1385

[14] Wunderle M, Gass P, Haberle L et al. BRCA mutations and their influence on pathological complete response and prognosis in a clinical cohort of neoadjuvantly treated breast cancer patients. Breast Cancer Res Treat 2018; 171: 85-94

[15] Hoyer ], Vasileiou G, Uebe S et al. Addition of triple negativity of breast cancer as an indicator for germline mutations in predisposing genes increases sensitivity of clinical selection criteria. BMC Cancer 2018; 18: 926

[16] Baselga J, Campone M, Piccart M et al. Everolimus in postmenopausal hormone-receptor-positive advanced breast cancer. N Engl J Med 2012; 366: $520-529$

[17] Tesch H, Stoetzer O, Decker T et al. Efficacy and safety of everolimus plus exemestane in postmenopausal women with hormone receptor-positive, human epidermal growth factor receptor 2-negative locally advanced or metastatic breast cancer: Results of the single-arm, phase IIIB 4EVER trial. Int J Cancer 2019; 144: 877-885

[18] Banys-Paluchowski M, Krawczyk N, Paluchowski P. Cyclin-dependent kinase 4/6 inhibitors: what have we learnt across studies, therapy situations and substances. Curr Opin Obstet Gynecol 2019; 31: 56-66

[19] Turner NC, Slamon DJ, Ro J et al. Overall Survival with Palbociclib and Fulvestrant in Advanced Breast Cancer. N Engl J Med 2018; 379: 1926-1936

[20] Muller V, Nabieva N, Haberle L et al. Impact of disease progression on health-related quality of life in patients with metastatic breast cancer in the PRAEGNANT breast cancer registry. Breast 2018; 37: 154-160

[21] Rugo HS, Dieras V, Gelmon KA et al. Impact of palbociclib plus letrozole on patient-reported health-related quality of life: results from the PALOMA-2 trial. Ann Oncol 2018; 29: 888-894

[22] Huober J, Fasching PA, Taran FA et al. Factors associated with first line chemotherapy use in patients with hormone receptor positive, HER2 negative metastatic breast cancer - data from the PRAEGNANT breast cancer registry. Cancer Res 2018. doi:10.1158/1538-7445.SABCS1117P1153-1111-1107

[23] Hartkopf AD, Huober J, Volz B et al. Treatment landscape of advanced breast cancer patients with hormone receptor positive HER2 negative tumors - Data from the German PRAEGNANT breast cancer registry. Breast 2018; 37: 42-51

[24] Cancer Genome Atlas Network. Comprehensive molecular portraits of human breast tumours. Nature 2012; 490: 61-70
[25] Lux MP, Fasching PA, Schrauder MG et al. The PI3K Pathway: Background and Treatment Approaches. Breast Care (Basel) 2016; 11: 398-404

[26] O'Leary B, Cutts RJ, Liu Y et al. The Genetic Landscape and Clonal Evolution of Breast Cancer Resistance to Palbociclib plus Fulvestrant in the PALOMA-3 Trial. Cancer Discov 2018; 8: 1390-1403

[27] André F, Ciruelos E, Rubovszky G et al. Alpelisib (ALP) + fulvestrant (FUL) for advanced breast cancer $(A B C)$ : results of the Phase 3 SOLAR- 1 trial. Proceedings of the ESMO Conference 2018. Ann Oncol 2018; Abstr. LBA3_PR

[28] Juric D, Ciruelos E, Rubovszky G et al. Alpelisib + fulvestrant for advanced breast cancer: Subgroup analyses from the phase III SOLAR-1 trial. San Antonio Breast Cancer Symposium 2018; Abstr. GS3-08

[29] Slamon DJ, Clark GM, Wong SG et al. Human breast cancer: correlation of relapse and survival with amplification of the HER-2/neu oncogene. Science 1987; 235: 177-182

[30] Slamon D, Eiermann W, Robert $\mathrm{N}$ et al. Adjuvant trastuzumab in HER2positive breast cancer. N Engl J Med 2011; 365: 1273-1283

[31] Slamon D], Leyland-Jones B, Shak S et al. Use of chemotherapy plus a monoclonal antibody against HER2 for metastatic breast cancer that overexpresses HER2. N Engl J Med 2001; 344: 783-792

[32] Connell CM, Doherty G]. Activating HER2 mutations as emerging targets in multiple solid cancers. ESMO Open 2017; 2: e000279

[33] Konecny G, Pauletti G, Pegram M et al. Quantitative association between HER-2/neu and steroid hormone receptors in hormone receptor-positive primary breast cancer. J Natl Cancer Inst 2003; 95: 142-153

[34] Loibl S, von Minckwitz G, Schneeweiss A et al. PIK3CA mutations are associated with lower rates of pathologic complete response to anti-human epidermal growth factor receptor 2 (her2) therapy in primary HER2-overexpressing breast cancer. J Clin Oncol 2014; 32: 3212-3220

[35] Musolino A, Naldi N, Bortesi B et al. Immunoglobulin G fragment C receptor polymorphisms and clinical efficacy of trastuzumab-based therapy in patients with HER-2/neu-positive metastatic breast cancer. J Clin Oncol 2008; 26: 1789-1796

[36] Schettini F, Buono G, Cardalesi C et al. Hormone Receptor/Human Epidermal Growth Factor Receptor 2-positive breast cancer: Where we are now and where we are going. Cancer Treat Rev 2016; 46: 20-26

[37] Nuciforo P, Thyparambil S, Aura C et al. High HER2 protein levels correlate with increased survival in breast cancer patients treated with antiHER2 therapy. Mol Oncol 2016; 10: 138-147

[38] Swain SM, Kim SB, Cortes J et al. Pertuzumab, trastuzumab, and docetaxel for HER2-positive metastatic breast cancer (CLEOPATRA study): overall survival results from a randomised, double-blind, placebo-controlled, phase 3 study. Lancet Oncol 2013; 14: 461-471

[39] Swain SM, Baselga J, Kim SB et al. Pertuzumab, trastuzumab, and docetaxel in HER2-positive metastatic breast cancer. N Engl J Med 2015; 372: 724-734

[40] Baselga J, Cortes J, Kim SB et al. Pertuzumab plus trastuzumab plus docetaxel for metastatic breast cancer. N Engl J Med 2012; 366: 109-119

[41] Verma S, Miles D, Gianni L et al. Trastuzumab emtansine for HER2-positive advanced breast cancer. N Engl J Med 2012; 367: 1783-1791

[42] Wockel A, Festl J, Stuber T et al. Interdisciplinary Screening, Diagnosis, Therapy and Follow-up of Breast Cancer. Guideline of the DGGG and the DKG (S3-Level, AWMF Registry Number 032/045OL, December 2017) - Part 2 with Recommendations for the Therapy of Primary, Recurrent and Advanced Breast Cancer. Geburtsh Frauenheilk 2018; 78: 1056-1088

[43] Fasching PA, Brucker SY, Fehm TN et al. Biomarkers in Patients with Metastatic Breast Cancer and the PRAEGNANT Study Network. Geburtsh Frauenheilk 2015; 75: 41-50

[44] Lux MP, Nabieva N, Hartkopf AD et al. Therapy Landscape in Patients with Metastatic HER2-Positive Breast Cancer: Data from the PRAEGNANT Real-World Breast Cancer Registry. Cancers (Basel) 2018. doi:10.3390/ cancers 11010010 
[45] Takegawa N, Nonagase Y, Yonesaka K et al. DS-8201a, a new HER2-targeting antibody-drug conjugate incorporating a novel DNA topoisomerase I inhibitor, overcomes HER2-positive gastric cancer T-DM1 resistance. Int J Cancer 2017; 141: 1682-1689

[46] Doi T, Shitara K, Naito Y et al. Safety, pharmacokinetics, and antitumour activity of trastuzumab deruxtecan (DS-8201), a HER2-targeting antibody-drug conjugate, in patients with advanced breast and gastric or gastro-oesophageal tumours: a phase 1 dose-escalation study. Lancet Oncol 2017; 18: 1512-1522

[47] Iwata H, Tamura K, Doi T et al. Trastuzumab deruxtecan (DS-8201a) in subjects with HER2-expressing solid tumors: Long-term results of a large phase 1 study with multiple expansion cohorts. J Clin Oncol 2018. doi:10.1200/JCO.2018.1236.1215_suppl.2501

[48] Powell CA, Camidge DR, Gemma A et al. Characterization, monitoring, and management of interstitial lung disease in patients with metastatic breast cancer: Analysis of data available from multiple studies of DS8201a, a HER2-targeted antibody drug conjugate with a topoisomerase I inhibitor payload. San Antonio Breast Cancer Symposium 2018; Abstr. P6-17-06

[49] Schneeweiss A, Lux MP, Hartkopf AD et al. Progression free survival (PFS) and overall survival (OS) of patients treated with trastuzumab emtansine (T-DM1) after previous treatment with pertuzumab in patients with advanced breast cancer (NCT02338167). San Antonio Breast Cancer Symposium 2018; Abstr. P6-17-22

[50] Witzel I, Laakmann E, Weide R et al. Treatment and outcomes of patients in the Brain Metastases in Breast Cancer Network Registry. Eur J Cancer 2018; 102: 1-9

[51] Sperduto PW, Kased N, Roberge D et al. Summary report on the graded prognostic assessment: an accurate and facile diagnosis-specific tool to estimate survival for patients with brain metastases. J Clin Oncol 2012; 30: 419-425

[52] Witzel ID, Riecke K, Laakmann E et al. Validation of different prognostic scores in breast cancer patients with brain metastases of the BMBC registry (GBG-79). San Antonio Breast Cancer Symposium 2018; Abstr. P4-08-26

[53] Tolaney SM, Sahebjam S, Le Rhun E et al. A phase 2 study of abemaciclib in patients with leptomeningeal metastases secondary to HR+, HER2breast cancer. San Antonio Breast Cancer Symposium 2018; Abstr. P119-07

[54] Braun S, Vogl FD, Naume B et al. A pooled analysis of bone marrow micrometastasis in breast cancer. N Engl J Med 2005; 353: 793-802

[55] Trapp E, Janni W, Schindlbeck C et al. Presence of Circulating Tumor Cells in High-Risk Early Breast Cancer During Follow-Up and Prognosis. J Natl Cancer Inst 2018. doi:10.1093/jnci/djy152

[56] Huebner H, Fasching PA, Gumbrecht W et al. Filtration based assessment of CTCs and CellSearch(R) based assessment are both powerful predictors of prognosis for metastatic breast cancer patients. BMC Cancer 2018; 18: 204

[57] Polasik A, Tzschaschel M, Schochter F et al. Circulating Tumour Cells, Circulating Tumour DNA and Circulating MicroRNA in Metastatic Breast Carcinoma - What is the Role of Liquid Biopsy in Breast Cancer? Geburtsh Frauenheilk 2017; 77: 1291-1298

[58] Janni W], Rack B, Terstappen LW et al. Pooled Analysis of the Prognostic Relevance of Circulating Tumor Cells in Primary Breast Cancer. Clin Cancer Res 2016; 22: 2583-2593

[59] Janni W, Rack B, Fasching P et al. Persistence of circulating tumor cells in high risk early breast cancer patients during follow-up care suggests poor prognosis - Results from the adjuvant SUCCESS A trial. Cancer Res 2016. doi:10.1158/1538-7445.SABCS15-S2-03

[60] Rack B, Schindlbeck C, Juckstock J et al. Circulating tumor cells predict survival in early average-to-high risk breast cancer patients. J Natl Cancer Inst 2014. doi:10.1093/jnci/dju066
[61] Muller V, Riethdorf S, Rack B et al. Prognostic impact of circulating tumor cells assessed with the CellSearch System and AdnaTest Breast in metastatic breast cancer patients: the DETECT study. Breast Cancer Res 2012; 14: R118

[62] Hosseini H, Obradovic MM, Hoffmann M et al. Early dissemination seeds metastasis in breast cancer. Nature 2016. doi:10.1038/nature20785

[63] Hartkopf AD, Brucker SY, Taran FA et al. International pooled analysis of the prognostic impact of disseminated tumor cells from the bone marrow in early breast cancer: Results from the PADDY study. San Antonio Breast Cancer Symposium 2018; Abstr. GS5-07

[64] Bidard FC, Peeters DJ, Fehm T et al. Clinical validity of circulating tumour cells in patients with metastatic breast cancer: a pooled analysis of individual patient data. Lancet Oncol 2014; 15: 406-414

[65] Bidard FC, Jacot W, Dureau S et al. Clinical utility of circulating tumor cell count as a tool to chose between first line hormone therapy and chemotherapy for ER+ HER2- metastatic breast cancer: Results of the phase III STIC CTC trial. San Antonio Breast Cancer Symposium 2018; Abstr. GS307

[66] Ganz PA, Yip CH, Gralow JR et al. Supportive care after curative treatment for breast cancer (survivorship care): resource allocations in lowand middle-income countries. A Breast Health Global Initiative 2013 consensus statement. Breast 2013; 22: 606-615

[67] Cardoso F, Bese N, Distelhorst SR et al. Supportive care during treatment for breast cancer: resource allocations in low- and middle-income countries. A Breast Health Global Initiative 2013 consensus statement. Breast 2013; 22: 593-605

[68] Harrison JD, Young JM, Price MA et al. What are the unmet supportive care needs of people with cancer? A systematic review. Support Care Cancer 2009; 17: 1117-1128

[69] Beesley VL, Alemayehu C, Webb PM. A systematic literature review of the prevalence of and risk factors for supportive care needs among women with gynaecological cancer and their caregivers. Support Care Cancer 2018; 26: 701-710

[70] Distelhorst SR, Cleary JF, Ganz PA et al. Optimisation of the continuum of supportive and palliative care for patients with breast cancer in low-income and middle-income countries: executive summary of the Breast Health Global Initiative, 2014. Lancet Oncol 2015; 16: e137-e147

[71] Aapro MS, Bohlius ], Cameron DA et al. 2010 update of EORTC guidelines for the use of granulocyte-colony stimulating factor to reduce the incidence of chemotherapy-induced febrile neutropenia in adult patients with lymphoproliferative disorders and solid tumours. Eur J Cancer 2011; 47: 8-32

[72] Olver I, Clark-Snow RA, Ballatori E et al. Guidelines for the control of nausea and vomiting with chemotherapy of low or minimal emetic potential. Support Care Cancer 2011; 19 (Suppl. 1): S33-S36

[73] Jordan K, Roila F, Molassiotis A et al. Antiemetics in children receiving chemotherapy. MASCC/ESMO guideline update 2009. Support Care Cancer 2011; 19 (Suppl. 1): S37-S42

[74] Jordan K, Aapro M, Kaasa S et al. European Society for Medical Oncology (ESMO) position paper on supportive and palliative care. Ann Oncol 2018; 29: 36-43

[75] Hesketh P], Kris MG, Basch E et al. Antiemetics: American Society of Clinical Oncology Clinical Practice Guideline Update. J Clin Oncol 2017; 35: 3240-3261

[76] Feyer PC, Maranzano E, Molassiotis A et al. Radiotherapy-induced nausea and vomiting (RINV): MASCC/ESMO guideline for antiemetics in radiotherapy: update 2009. Support Care Cancer 2011; 19 (Suppl. 1): S5-S14

[77] de Wit M, Ortner P, Lipp HP et al. Management of cytotoxic extravasation - ASORS expert opinion for diagnosis, prevention and treatment. Onkologie 2013; 36: 127-135

[78] Bossi P, Antonuzzo A, Cherny $\mathrm{NI}$ et al. Diarrhoea in adult cancer patients: ESMO Clinical Practice Guidelines. Ann Oncol 2018; 29: iv126-iv142 
[79] Slamon D], Eiermann W, Robert NJ et al. Ten year follow-up of BCIRG-006 comparing doxorubicin plus cyclophosphamide followed by docetaxel ( $\mathrm{AC}->\mathrm{T}$ ) with doxorubicin plus cyclophosphamide followed by docetaxel and trastuzumab (AC $\rightarrow \mathrm{TH}$ ) with docetaxel, carboplatin and trastuzumab (TCH) in HER2+early breast cancer. Cancer Res 2016. doi:10.1158/1538-7445.SABCS1115-S1155-1104

[80] Janni W, Nitz U, Rack BK et al. Pooled analysis of two randomized phase III trials (PlanB/SuccessC) comparing six cycles of docetaxel and cyclophosphamide to sequential anthracycline taxane chemotherapy in patients with intermediate and high risk HER2-negative early breast cancer $(n=5,923)$. J Clin Oncol 2018; 36: 522. doi:510.1200/ JCO.2018.1236.1215_suppl.1522

[81] Munster P, Krischer J, Tamura R et al. A randomized community-based trial of an angiotensin converting enzyme inhibitor, lisinopril or a beta blocker, carvedilol for the prevention of cardiotoxicity in patients with early stage HER2-positive breast cancer receiving adjuvant trastuzumab. San Antonio Breast Cancer Symposium 2018; Abstr. GS5-01

[82] Nabieva N, Kellner S, Fehm T et al. Influence of patient and tumor characteristics on early therapy persistence with letrozole in postmenopausal women with early breast cancer: results of the prospective Evaluate-TM study with 3941 patients. Ann Oncol 2018; 29: 186-192

[83] Nabieva N, Fehm T, Haberle L et al. Influence of side-effects on early therapy persistence with letrozole in post-menopausal patients with early breast cancer: Results of the prospective EvAluate-TM study. Eur J Cancer 2018; 96: 82-90

[84] Chirgwin JH, Giobbie-Hurder A, Coates AS et al. Treatment Adherence and Its Impact on Disease-Free Survival in the Breast International Group 1-98 Trial of Tamoxifen and Letrozole, Alone and in Sequence. J Clin Oncol 2016; 34: 2452-2459

[85] Buser KS, Joss RA, Piquet D et al. Oral ondansetron in the prophylaxis of nausea and vomiting induced by cyclophosphamide, methotrexate and 5 -fluorouracil (CMF) in women with breast cancer. Results of a prospective, randomized, double-blind, placebo-controlled study. Ann Oncol 1993; 4: 475-479

[86] Schilling J, Hielscher C, Hanusch C et al. Efficacy of NEPA as antiemetic prophylaxis in breast cancer patients receiving highly or moderately emetogenic chemotherapy - Interim results of a German prospective, noninterventional study. San Antonio Breast Cancer Symposium 2018; Abstr. P1-11-10

[87] Fasching PA, Kollmannsberger B, Strissel PL et al. Polymorphisms in the novel serotonin receptor subunit gene HTR3C show different risks for acute chemotherapy-induced vomiting after anthracycline chemotherapy. J Cancer Res Clin Oncol 2008; 134: 1079-1086

[88] Hammer C, Fasching PA, Loehberg CR et al. Polymorphism in HTR3D shows different risks for acute chemotherapy-induced vomiting after anthracycline chemotherapy. Pharmacogenomics 2010; 11: 943-950

[89] Kollmannsberger B, Lohberg C, Stohlmacher J et al. Prediction of emesis by polymorphisms in the serotonin receptor subunit gene HTR3C - Rationale for an international prospective pharmacogenomics study Emesis 2 - CINV. Onkologie 2008; 31: 27-28
[90] Lopez-Morales P, Flores-Funes D, Sanchez-Migallon EG et al. Genetic Factors Associated with Postoperative Nausea and Vomiting: a Systematic Review. J Gastrointest Surg 2018; 22: 1645-1651

[91] Sparano JA, Gray RJ, Makower DF et al. Adjuvant Chemotherapy Guided by a 21-Gene Expression Assay in Breast Cancer. N Engl J Med 2018; 379: 111-121

[92] Wagner LI, Gray RJ, Garcia S et al. Symptoms and health-related quality of life on endocrine therapy alone (E) versus chemoendocrine therapy $(\mathrm{C}+\mathrm{E})$ : TAILORx patient-reported outcomes results. San Antonio Breast Cancer Symposium 2018; Abstr. GS6-03

[93] Janni W, Rack BK, Friedl TW et al. Lifestyle Intervention and Effect on Disease-free Survival in Early Breast Cancer Pts: Interim Analysis from the Randomized SUCCESS C Study. San Antonio Breast Cancer Symposium 2018; Abstr. GS5-03

[94] Thune I, Husoy A, Frydenberg $\mathrm{H}$ et al. Cardiovascular function and the effect of exercise training during adjuvant breast cancer treatment. Results from The EBBA-II trial. San Antonio Breast Cancer Symposium 2018; Abstr. GS5-02

[95] Hurria A, Magnuson A, Gross CP et al. Development and validation of a chemotherapy toxicity (Chemo Tox) risk score for older patients (Pts) with breast cancer $(\mathrm{BC})$ receiving adjuvant/neoadjuvant treatment (Adjuvant Tx): A R01 and BCRF funded prospective multicenter study. San Antonio Breast Cancer Symposium 2018; Abstr. GS6-04

[96] Schmidt M, Fasching PA, Beckmann MW et al. Biomarkers in Breast Cancer - An Update. Geburtsh Frauenheilk 2012; 72: 819-832

[97] Andre F, Filleron T, $\mathrm{Ng} \mathrm{C}$ et al. Genomic characterisation of metastatic breast cancer. San Antonio Breast Cancer Symposium 2018; Abstr. GS1-08

[98] Andre F, Bachelot T, Commo F et al. Comparative genomic hybridisation array and DNA sequencing to direct treatment of metastatic breast cancer: a multicentre, prospective trial (SAFIR01/UNICANCER). Lancet Oncol 2014; 15: 267-274

[99] Le Tourneau C, Delord JP, Goncalves A et al. Molecularly targeted therapy based on tumour molecular profiling versus conventional therapy for advanced cancer (SHIVA): a multicentre, open-label, proof-of-concept, randomised, controlled phase 2 trial. Lancet Oncol 2015; 16: 1324-1334

[100] Massard C, Michiels S, Ferte $C$ et al. High-Throughput Genomics and Clinical Outcome in Hard-to-Treat Advanced Cancers: Results of the MOSCATO 01 Trial. Cancer Discov 2017; 7: 586-595

[101] Wunderle M, Olmes G, Nabieva N et al. Risk, Prediction and Prevention of Hereditary Breast Cancer - Large-Scale Genomic Studies in Times of Big and Smart Data. Geburtsh Frauenheilk 2018; 78: 481-492

[102] Shimelis H, LaDuca H, Hu C et al. Triple-Negative Breast Cancer Risk Genes Identified by Multigene Hereditary Cancer Panel Testing. J Natl Cancer Inst 2018. doi:10.1093/jnci/djy106

[103] Hein A, Gass P, Walter CB et al. Computerized patient identification for the EMBRACA clinical trial using real-time data from the PRAEGNANT network for metastatic breast cancer patients. Breast Cancer Res Treat 2016; 158: 59-65

[104] Tresp V, Overhage JM, Bundschus M et al. Going Digital: A Survey on Digitalization and Large-Scale Data Analytics in Healthcare. P IEEE 2016; 104: 2180-2206 